\title{
The Relationship between Serum Leukotriene B4 and High-Sensitivity C-Reactive Protein Expression Levels and Adverse Reactions in Patients with Colon Cancer During Perioperative Blood Transfusion
}

\author{
XIAOLAN LI AND YI LUO ${ }^{1 *}$
}

Department of Medical Clinical Laboratory, The First People's Hospital of Chongqing Liang Jiang New Area, ${ }^{1}$ Department of Blood Transfusion, Three Gorges Hospital, Chongqing University, Chongqing 404000, China

Li et al.: Relationship between Serum Leukotriene B4 and High-Sensitivity C-Reactive Protein Expression Levels

\begin{abstract}
To explore the predictive value of serum high-sensitivity C-reactive protein and leukotriene B4 in perioperative blood transfusion patients with colon cancer in patients with adverse blood transfusion reactions. 168 patients undergoing colon cancer surgery in a hospital from March 2018 to March 2020 were selected as the research objects and checked the levels of high-sensitivity C-reactive protein and leukotriene B4 in the venous blood of all patients. There were 73 cases in the adverse blood transfusion group (experimental group) and 95 cases in the non-transfusion reaction group (control group). The serum levels of high-sensitivity $\mathrm{C}$-reactive protein and leukotriene B4 in the two groups were compared. Based on the analysis of the basic data of the two groups of patients, serum high-sensitivity $\mathrm{C}$-reactive protein and leukotriene $\mathrm{B} 4$ are independent risk factors for perioperative adverse reactions in colon cancer patients. The levels of serum high-sensitivity $\mathrm{C}$-reactive protein and leukotriene $\mathrm{B} 4$ in the experimental group are higher than those in the normal group and there are differences, both were statistically significant $(p<0.05)$; receiver operating characteristic curve results showed that the area under the curve of high-sensitivity $\mathrm{C}$-reactive protein and leukotriene $\mathrm{B} 4$ alone and in combination to predict adverse transfusion reactions were $0.733,0.819$ and 0.877 , respectively. The area under the curve of combined factor diagnosis was greater than single diagnosis; serum high-sensitivity $\mathrm{C}$-reactive protein $\geq 14.64 \mathrm{mg} / \mathrm{l}$ and leukotriene $B 4 \geq 18.86 \mathrm{pg} / \mathrm{l}$ are risk factors for adverse reactions in patients with colon cancer perioperative blood transfusion. Elevated serum high-sensitivity $\mathrm{C}$-reactive protein and leukotriene B4 in patients with colon cancer during perioperative blood transfusion are risk factors for adverse blood transfusion reactions. High-sensitivity C-reactive protein $\geq 14.64 \mathrm{mg} / \mathrm{l}$ and leukotriene $\mathrm{B} 4 \geq 18.86 \mathrm{pg} / \mathrm{l} \mathrm{suggest}$ that adverse blood transfusion reactions may occur. The combination of the two can increase the incidence of adverse blood transfusion reactions.
\end{abstract}

Key words: Leukotriene B4, high-sensitivity C-reactive protein, colon cancer, adverse blood transfusion reactions

Blood transfusion is a treatment method that saves the lives of patients and it has been widely developed clinically $^{[1]}$. However, there may be related adverse blood transfusion reactions in patients during the blood transfusion process. Adverse blood transfusion reactions refer to the symptoms and signs related to blood transfusion, occurred during the blood transfusion or after the blood transfusion or the abnormal symptoms and symptoms that cannot be explained by the original disease ${ }^{[2-4]}$. Physical signs, adverse blood transfusion reactions are one of the life-threatening complications of blood transfusion, the most common of which are allergic reactions, fever reactions and hemolytic reactions. Studies have pointed out that blood type incompatibility is the main cause of hemolytic reactions in patients. In addition, even with mild allergic reactions, the risk of death in blood transfusion patients will greatly increase ${ }^{[5,6]}$. According to the time of symptom onset, adverse blood transfusion reactions can be divided into immediate transfusion reactions and delayed transfusion type blood transfusion reaction ${ }^{[7]}$. Therefore, the adverse

*Address for correspondence

E-mail: luoyi_5132@163.com 
blood transfusion reaction can be diagnosed as soon as possible and accurately, so that preventive measures can be obtained faster and the outcome of the patient's adverse blood transfusion reaction can be improved in time ${ }^{[8,9]}$. High-sensitivity C-Reactive Protein (hsCRP) and leukotriene B4 (LTB4) are factors related to inflammation and immunity ${ }^{[10,11]}$. Studies have shown that the combined detection of eotaxin and LTB4 in serum is related to the occurrence of adverse blood transfusion reactions ${ }^{[12]}$ and its serum markers. There are few studies that predict the occurrence of related blood transfusion reactions ${ }^{[13,14]}$. Studies have shown that the type of blood transfusion, the time of blood transfusion, the history of blood transfusion and the history of blood diseases, etc., will increase the incidence of adverse blood transfusion reactions. Colon cancer perioperative or intraoperative blood transfusion is large and the possibility of adverse blood transfusion reactions is high ${ }^{[15]}$. This study is based on colon cancer patients. By detecting the levels of hs-CRP and LTB4 in the serum of colon cancer patients and analyzing its relationship with the occurrence of blood transfusion reactions, this study hopes to find serum markers for early prediction of adverse blood transfusion reactions in colon cancer patients undergoing blood transfusion.

\section{MATERIALS AND METHODS}

\section{General information:}

Selected patients, who were diagnosed with colon cancer in our hospital from March 2018 to March 2020 and all required radical resection of surgery, all required blood transfusion during the perioperative period. Among all colon cancer perioperative blood transfusion patients, 73 patients with blood transfusion reactions were selected into the experimental group and 95 patients without blood transfusion reactions during the same period were selected into the control group. The general data of the two groups of patients are comparable (Table 1). The research protocol has been approved by the hospital ethics committee, all patients included in the experimental group or the control group communicated with their family members.

TABLE 1: COMPARISON OF BASELINE DATA OF TWO GROUPS OF PREGNANT WOMEN

\begin{tabular}{|c|c|c|c|c|}
\hline Project & $\begin{array}{l}\text { Experimental group } \\
\text { (73 cases) }\end{array}$ & $\begin{array}{l}\text { Control group (95 } \\
\text { cases) }\end{array}$ & $\mathrm{t} / \chi^{2}$ value & $\mathrm{p}$ value \\
\hline Age & $44.37 \pm 9.64$ & $47.03 \pm 10.05$ & 1.867 & 0.205 \\
\hline Gender (M/F) & $43 / 30$ & $52 / 43$ & 1.341 & 0.196 \\
\hline BMI & $22.97 \pm 2.94$ & $22.35 \pm 3.04$ & 0.892 & 0.791 \\
\hline $\begin{array}{l}\text { Past blood transfusion } \\
\text { history }\end{array}$ & & & 0.745 & 0.662 \\
\hline Yes & 35 (47.95\%) & 44 (47.95 \%) & & \\
\hline No & 38 (52.05\%) & 51 (47.95 \%) & & \\
\hline $\begin{array}{l}\text { Past blood transfusion } \\
\text { allergy history }\end{array}$ & & & 4.671 & 0.015 \\
\hline Yes & $14(19.18 \%)$ & $6(6.32 \%)$ & 4.671 & 0.015 \\
\hline No & $21(28.77 \%)$ & $38(40.0 \%)$ & & \\
\hline History of drug allergy & & & 2.315 & 0.042 \\
\hline Yes & $10(13.70 \%)$ & $6(6.32 \%)$ & & \\
\hline No & $63(86.30 \%)$ & $89(93.68 \%)$ & & \\
\hline $\begin{array}{l}\text { Blood transfusion } \\
\text { components }\end{array}$ & & & 4.671 & 0.008 \\
\hline Platelets & $10(13.70 \%)$ & $3(3.16 \%)$ & & \\
\hline Cryoprecipitate & $19(26.03 \%)$ & $2(2.11 \%)$ & & \\
\hline Frozen plasma & 52 (71.23 \%) & 86 (90.53 \%) & & \\
\hline $\begin{array}{l}\text { Suspended red blood } \\
\text { cells }\end{array}$ & $46(63.01 \%)$ & $59(62.11 \%)$ & & \\
\hline Wash red blood cells & $5(6.85 \%)$ & $0(0.00 \%)$ & & \\
\hline Other & $9(12.33 \%)$ & $11(11.58 \%)$ & & \\
\hline
\end{tabular}


www.ijpsonline.com

\begin{tabular}{|c|c|c|c|}
\hline Blood transfusion & $1328.53 \pm 362.03$ & $1296.05 \pm 254.78$ & 0.442 \\
\hline Basic illness & & & 3.605 \\
\hline Immune disease & $5(6.85 \%)$ & $1(1.05 \%)$ & \\
\hline Blood disease & 24 (32.88 \%) & $6(6.32 \%)$ & \\
\hline Other underlying & $21(28.77 \%)$ & $19(20.00 \%)$ & \\
\hline
\end{tabular}

\section{Research objects:}

Inclusion criteria: Diagnosis according to "Blood transfusion therapy"; Allergic reactions: Local or systemic skin itching, dyspnea, abdominal pain and diarrhea and other unexplainable symptoms; Nonhemolytic febrile reaction: Blood transfusion fever occurs within 1 to $2 \mathrm{~h}$ after transfusion and the body temperature can reach $39-40^{\circ}$ and the duration is within 2 h; Hemolytic reaction: Early headache, chest pain, chills, high fever, shortness of breath, etc., severe shock, hemoglobinuria, acute renal failure and other symptoms.

Exclusion criteria: No other malignant tumors in the whole body except colon cancer; complicated with serious heart, lung and other medical diseases; pregnant women and psychiatric patients; patients who cannot actively cooperate, patients who use drugs that affect serum hs-CRP and LTB4 within the past week.

\section{Research method:}

Standards for blood transfusion: According to the relevant regulations of the blood transfusion department of our hospital on the indications for blood transfusion, the indications for leukocyte suspension red blood cell transfusion: The patient's hemoglobin, platelets and coagulation function before surgery are normal and the patient's intraoperative blood loss exceeds $600 \mathrm{ml}$; after the patient, hemoglobin $(\mathrm{Hb})<80 \mathrm{~g} / 1$ was rechecked after operation, bloody fluid was continuously drawn from the abdominal drainage tube and hemoglobin was continuously decreased during dynamic recheck. Indications for frozen plasma infusion: Continuous bleeding from the wound during operation, drainage after operation, continuous bleeding in the tube (reexamination of coagulation function abnormality, the Prothrombin Time (PT) delay $>3$ s, Activated Partial Thromboplastin Time (APTT) $>1.5$ times, the International Normalized Ratio (INR) prolongation is greater than 2 times) and Disseminated Intravascular Coagulation (DIC), etc.; abnormal liver function associated with wound hemorrhage and other related basic diseases, etc., plasma infusion can be used as note for prevention.
Sample collection and measurement: In the early morning on an empty stomach, all subjects were subjected to $3 \mathrm{ml}$ elbow venous blood in an anticoagulation tube. After adding the anticoagulant, the supernatant was centrifuged at $3000 \mathrm{r} / \mathrm{min}$ for 10 min and the supernatant was retained and stored at $-80^{\circ}$ for testing. Subsequently, an Enzyme-Linked Immunosorbent Assay (ELISA) kit (provided by Diagnostica Stago) was used to detect the levels of hs-CRP and LTB4 in the serum of all patients. The ELISA kit in the experiment was purchased from R\&D Systems in the United States. All tests are completed by professional laboratory personnel in accordance with the instructions and instrument operating specifications.

Observation indicators: Detect the hs-CRP and LTB4 expression levels in the serum of the two groups of patients by univariate analysis, multivariate logistic regression to confirm the risk factors of blood transfusion reaction and use Receiver Operating Characteristic (ROC) curve to evaluate whether hs-CRP and LTB4 alone and in combination, predict the value of adverse blood transfusion reactions.

\section{Statistical analysis:}

The data was analyzed by Statistical Package For The Social Sciences (SPSS) 25.0 software. Qualitative data is expressed as mean \pm standard deviation $(\mathrm{x} \pm \mathrm{s})$ and quantitative data is expressed as frequency (percent) [n (\%)]. The independent sample t test was used to compare the measurement data between the two groups and the $\chi^{2}$ test was used to count the data. The ROC curve was used to evaluate the predictive value of hsCRP and LTB4 alone and in combination on the adverse effects of perioperative blood transfusion. Then pass and calculate the cut-off value and use logistic regression model to analyze the correlation between hs-CRP, LTB4 and adverse blood transfusion reactions, $p<0.05$ indicates that the difference is statistically significant.

\section{RESULTS AND DISCUSSION}

Compare the two groups of patients with baseline data such as age, gender, Body Mass Index (BMI), previous blood transfusion history, previous blood transfusion allergy history, drug allergy history, blood 
www.ijpsonline.com

TABLE 2: COMPARISON OF SERUM hS-CRP AND LTB4 LEVELS BETWEEN THE TWO GROUPS OF PATIENTS $(x \pm s)$

\begin{tabular}{lcccc}
\hline \multirow{2}{*}{ Group } & \multicolumn{2}{c}{$\mathrm{hs-CRP}(\mathrm{mg} / \mathrm{l})$} & \multicolumn{2}{c}{ LTB4 $(\mathrm{pg} / \mathrm{l})$} \\
\cline { 2 - 5 } & $\begin{array}{c}\text { Before blood } \\
\text { transfusion }\end{array}$ & After blood transfusion & $\begin{array}{c}\text { Before blood } \\
\text { transfusion }\end{array}$ & After blood transfusion \\
\hline $\begin{array}{l}\text { Experimental group }(73 \\
\text { cases) }\end{array}$ & $8.34 \pm 3.49$ & $20.57 \pm 6.57^{*}$ & $13.58 \pm 8.96$ & $27.89 \pm 11.04^{*}$ \\
$\begin{array}{l}\text { Control group (95 } \\
\text { cases) }\end{array}$ & $7.96 \pm 3.05$ & $9.05 \pm 3.36^{*}$ & $14.05 \pm 9.15$ & $16.86 \pm 9.68^{*}$ \\
t value & 0.669 & 9.461 & 0.561 & 8.442 \\
p value & 0.601 & $<0.001$ & 0.574 & $<0.001$ \\
\hline
\end{tabular}

Note: ${ }^{*} p<0.001$

TABLE 3: MULTIVARIATE LOGISTIC REGRESSION ANALYSIS RESULTS OF ADVERSE BLOOD TRANSFUSION REACTIONS

\begin{tabular}{|c|c|c|c|c|c|}
\hline Factor & $B$ & Wald $\chi^{2}$ & $p$ value & $\begin{array}{l}\text { Odds ratio (OR) } \\
\text { value }\end{array}$ & $95 \% \mathrm{Cl}$ \\
\hline hs-CRP (mg/l) & 1.113 & 15.132 & $<0.001$ & 2.516 & $1.245 \sim 3.632$ \\
\hline LTB4 (pg/l) & 1.463 & 10.452 & $<0.001$ & 2.746 & $1.397 \sim 5.146$ \\
\hline $\begin{array}{l}\text { Past blood } \\
\text { transfusion allergy } \\
\text { history }\end{array}$ & 0.531 & 0.904 & 0.062 & 1.812 & $0.535 \sim 2.251$ \\
\hline $\begin{array}{l}\text { History of drug } \\
\text { allergy }\end{array}$ & 0.068 & 0.834 & 0.115 & 1.464 & $0.792 \sim 3.046$ \\
\hline Basic illness & 1.342 & 0.713 & 0.069 & 0.758 & $0.345 \sim 1.953$ \\
\hline $\begin{array}{l}\text { Blood transfusion } \\
\text { components }\end{array}$ & 0.082 & 0.624 & 0.082 & 1.201 & $0.601 \sim 2.308$ \\
\hline
\end{tabular}

TABLE 4: ROC CURVE ANALYSIS OF hS-CRP, LTB4 AND THEIR COMBINATION IN THE PREDICTION OF ADVERSE BLOOD TRANSFUSION

\begin{tabular}{lccccc}
\hline Variable & AUC & $95 \% \mathrm{Cl}$ & Cutoff value & Sensitivity & Specificity \\
\hline hs-CRP & 0.733 & $0.613 \sim 0.833$ & 0.49 & $74.79 \%$ & $82.53 \%$ \\
LTB4 & 0.819 & $0.675 \sim 0.876$ & 0.51 & $76.69 \%$ & $84.14 \%$ \\
hs-CRP+LTB4 & 0.877 & $0.803 \sim 0.924$ & 0.58 & $78.24 \%$ & $89.61 \%$ \\
\hline
\end{tabular}

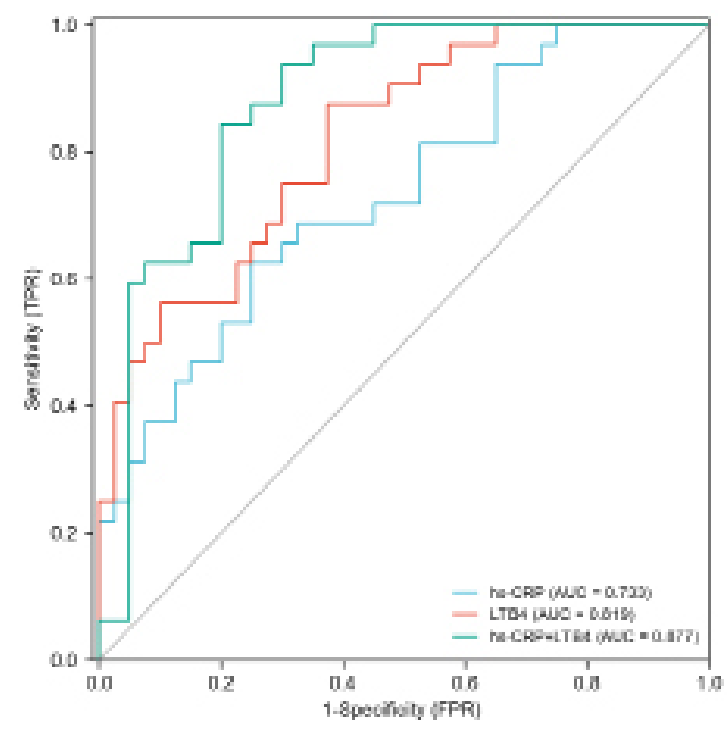

Fig. 1: Serum hs-CRP, LTB4 and the ROC curve for predicting the occurrence of adverse blood transfusion reactions 
transfusion components, blood transfusion volume and underlying diseases. The difference was not significant and not statistically significant $(\mathrm{p}>0.05)$. The two groups had significant differences in the history of blood transfusion allergy, history of drug allergy, blood transfusion components and underlying diseases, with statistical significance $(\mathrm{p}<0.05)$ (Table 1$)$.

Comparison of serum hs-CRP and LTB4 levels between the two groups of patients before and after blood transfusion was observed. Before blood transfusion, there was no significant difference in serum hs-CRP and LTB4 levels between the two groups of patients $(\mathrm{p}>0.05)$, after blood transfusion the hs-CRP and LTB4 in the experimental group were significantly higher than before blood transfusion with statistical significance $(p<0.05)$. The serum hs-CRP and LTB4 levels of the control group did not change much before and after blood transfusion, which was not statistically significant $(\mathrm{p}>0.05)$. The results are shown in Table 2 .

Multivariate logistic regression of adverse blood transfusion reactions were explained below. Taking the occurrence of adverse blood transfusion reactions as the dependent variable, the independent variables include serum hs-CRP (experimental group=1, control group=0) and serum LTB4 (experimental group $=1$, control group $=0$ ), which are significant. Differences in previous history of blood transfusion allergy (yes $=1, n o=0$ ), history of drug allergy (yes $=1$, no $=0$ ), underlying diseases (yes $=1, \mathrm{no}=0$ ) and blood transfusion components ( $>2$ two types $=1, \leq 2$ types $=0$ ), a stepwise logistic regression analysis was performed and the results showed that serum hs-CRP and LTB4 were independent risk factors for perioperative blood transfusion in patients with colon cancer (Table 3).

In order to further explore the predictive value of serum hs-CRP and LTB4, the occurrence of adverse blood transfusion reactions was used as the outcome variable, with a value of 1 , if it occurred and a value of 0 , if it did not occur and the single indicators of serum hs-CRP and LTB4, and the ROC curve of the combined response to blood transfusion. Serum hs-CRP and LTB4 are respectively $14.64 \mathrm{mg} / \mathrm{l}$ and $18.86 \mathrm{pg} / \mathrm{l}$ as the threshold value for prediction. ROC analysis results show that hs-CRP and LTB4 alone and in combination predict blood transfusion. The Area Under the Curve (AUC) of adverse reactions was $0.733,0.819$ and 0.877 . The combined factor diagnosis has the highest AUC, with a sensitivity of 0.782 , a specificity of 0.896 and a 95 $\%$ Confidence Interval (CI) of 0.803 and 0.924 . The specific results are shown in Table 4 and fig. 1.
Colon cancer is a common cancer in the digestive system. Due to the anatomical characteristics of the colon, tumors tend to invade blood vessels, increasing colon cancer's aggressiveness, high metastasis and recurrence. Therefore, most of these diseases are diagnosed as advanced, with poor prognosis and high recurrence rate ${ }^{[16,17]}$. At present, the treatment of colon cancer mainly relies on surgical treatment. There are abundant blood vessels in the colon, so there is a higher risk of bleeding during the operation. Frequent blood transfusions are required during the perioperative period $^{[18]}$. Studies have also shown that in $68 \%$ of patients with advanced colon cancer, the patient needs blood transfusion, which may cause changes in the patient's immune system, produce immunosuppression and increase the perioperative infection rate of blood transfusion patients ${ }^{[19]}$. Most scholars have shown that immune rejection is the main cause of adverse blood transfusion reactions and allergy and fever are the most common clinical manifestations of adverse reactions ${ }^{[20]}$. Studies have shown that patients with platelet transfusion have the highest incidence of adverse blood transfusion reactions and cryoprecipitate has the lowest incidence of adverse blood transfusion reactions ${ }^{[1,21]}$. Despite the current strict grasp of blood transfusion indications and operating specifications, adverse blood transfusion reactions still occur. Therefore, exploring certain serum markers to predict the occurrence of adverse blood transfusion reactions is extremely important and has far-reaching significance in avoiding the prognosis of blood transfusion reactions.

hs-CRP is an inflammation marker, which is an acute inflammatory protein. The serum hs-CRP level can reflect the systemic inflammatory response. If the patient's inflammatory response persists, then the hsCRP level will continue to rise ${ }^{[22]}$. Studies have shown that hs-CRP is a non-traditional risk factor to assess cardiovascular disease risk indicators. It also shows that depression in men is related to high levels of hs-CRP ${ }^{[23]}$. Studies have also found that the severity of diabetes is related to the hs-CRP in patient's free plasma, the increase of reactive protein (hs-CRP) is related ${ }^{[24]}$. Studies have shown that the long-term survival time of patients with esophageal cancer is negatively correlated with the level of hs-CRP in the patient's plasma before surgery. The decrease of hs-CRP level in serum indicates that the inflammatory state has improved. hsCRP is involved in the inflammatory reaction process of allergic reaction, respiratory system and cardiovascular system $^{[25]}$. Studies have shown that when a transfusion hemolysis reaction occurs, the level of LTB4 in the 
serum is abnormally increased ${ }^{[26]}$. Relevant studies have proved that the increase of hs-CRP and LTB4 in serum is related to the occurrence of adverse blood transfusion reactions ${ }^{[27]}$. It also shows that serum hsCRP and LTB4 are closely related to the occurrence of respiratory diseases. The method for serum detection of hs-CRP and LTB4 is enzyme-linked immunoassay ${ }^{[28]}$. This study included colon cancer patients. The study showed that after perioperative blood transfusion, there was no difference in serum hs-CRP and LTB4 values between the experimental group and the control group before blood transfusion ( $>00.05)$. After blood transfusion, the serum hs-CRP and LTB4 values of the experimental group was significantly higher than that of the control group $(\mathrm{p}<0.05)$, while serum hs-CRP and LTB4 in the control group were not significantly different before and after blood transfusion ( $p>0.05)$, indicating that hs-CRP and LTB4 are associated with colon cancer perioperative blood transfusion adverse reactions, there is a certain correlation. When the body has an adverse blood transfusion reaction, the body will have an antigen-antibody reaction, the white blood cells will be lysed and the inflammatory factors will be fully released, which will cause the serum hs-CRP and LTB4 of patients with colon cancer to increase.

The study also found that, in addition to serum hs-CRP and LTB4, the two groups had significant differences in the history of blood transfusion allergy, drug allergy history, blood transfusion components and underlying diseases, with statistical significance $(\mathrm{p}<0.05)$. The patient with a history of allergy to blood transfusion may be because of that when the patient is transfused again, the white blood cells will be lysed and inflammatory factors and allergens will be fully released and adverse reactions related to blood transfusion such as allergy and fever will occur. Studies have shown that there are differences in the incidence of adverse blood transfusion reactions in patients with different underlying diseases. Patients with past blood diseases have the highest incidence, which can reach $3 \%$, followed by immune diseases and adverse blood transfusion reactions up to $1.32 \%$. Studies have also shown that different blood types have different probabilities of adverse transfusion reactions. Adverse reactions are the highest in transfusion of apheresis platelets and the lowest in transfusion of washed red blood cells ${ }^{[29,30]}$.

In order to further confirm the value of serum hs-CRP and LTB4 in predicting adverse blood transfusion reactions, a stepwise logistic regression analysis was carried out and it was found that serum hs-CRP and LTB4 were independent risk factors for predicting adverse blood transfusion reactions. At the same time, single indicators of serum hs-CRP and LTB4 were drawn and the ROC curve of the combined response to blood transfusion. Serum hs-CRP and LTB4 are respectively $14.64 \mathrm{mg} / \mathrm{l}$ and $18.86 \mathrm{pg} / \mathrm{l}$ as the threshold value for prediction. ROC analysis results show that hs-CRP and LTB4 alone and in combination predict blood transfusion The AUC of adverse reactions was $0.733,0.819$ and 0.877 . The combined factor diagnosis has the highest AUC, with a sensitivity of 0.782 and a specificity of 0.896 .

In summary, serum hs-CRP and LTB4 can be used as serum markers to predict the occurrence of adverse transfusion reactions in patients with colon cancer perioperative blood transfusion. There are certain shortcomings in the single study. The sample size of the single center is still not enough. More samples are needed for prospective exploratory research and other serum indicators that affect transfusion reactions have not been fully included and further exploration is needed.

\section{Conflicts of interest:}

The authors declared no conflict of interest.

\section{REFERENCES}

1. Delaney M, Wendel S, Bercovitz RS, Cid J, Cohn C, Dunbar NM, et al. Transfusion reactions: prevention, diagnosis and treatment. Lancet 2016;388(10061):2825-36.

2. Palmieri TL. Burn injury and blood transfusion. Curr Opin Anaesthesiol 2019;32(2):247-51.

3. Semple JW, Rebetz J, Kapur R. Transfusion-associated circulatory overload and transfusion-related acute lung injury. Blood 2019;133(17):1840-53.

4. Raval JS, Griggs JR, Fleg A. Blood product transfusion in adults: indications, adverse reactions and modifications. Am Fam Physician 2020;102(1):30-8.

5. Goel R, Tobian AA, Shaz BH. Noninfectious transfusionassociated adverse events and their mitigation strategies. Blood 2019;133(17):1831-9.

6. Panch SR, Montemayor-Garcia C, Klein HG. Hemolytic transfusion reactions. N Engl J Med 2019;381(2):150-62.

7. DeLisle J. Is this a blood transfusion reaction? Don't hesitate; check it out. J Infus Nurs 2018;41(1):43-51.

8. Busch MP, Bloch EM, Kleinman S. Prevention of transfusiontransmitted infections. Blood 2019;133(17):1854-64.

9. Jiao C, Zheng L. Blood transfusion-related immunomodulation in patients with major obstetric haemorrhage. Vox Sang 2019;114(8):861-8.

10. Liao PY, Wu SH. Serum levels of IL-5 and LTB4 in children with Henoch-Schonlein purpura. Chin J Contemp Pediatr 2006;8(3):198-200. 
11. Zhao H, Gu H, Liu T, Ge J, Shi G. Analysis of curative effect of adjuvant therapy with bronchoalveolar lavage on COPD patients complicated with pneumonia. Exp Ther Med 2018;16(5):3799-804.

12. Hong M, Hong $\mathrm{C}$, Chen $\mathrm{H}, \mathrm{Ke} \mathrm{G}$, Huang J, Huang $\mathrm{X}$, et al. Effects of the Chinese herb formula Yufeining on stable chronic obstructive pulmonary disease: A randomized, doubleblind, placebo-controlled trial. Medicine 2018;97(39) e12461.

13. Sharma S, Sharma P, Tyler LN. Transfusion of blood and blood products: indications and complications. Am Fam Physician 2011;83(6):719-24.

14. Garraud O, Cognasse F, Laradi S, Hamzeh-Cognasse H, Peyrard T, Tissot JD, et al. How to mitigate the risk of inducing transfusion-associated adverse reactions. Transfus Clin Biol 2018;25(4):262-8.

15. Aubron C, Aries P, Le Niger C, Sparrow RL, Ozier Y. How clinicians can minimize transfusion-related adverse events? Transfus Clin Biol 2018;25(4):257-61.

16. Benson AB, Venook AP, Al-Hawary MM, Cederquist L, Chen YJ, Ciombor KK, et al. NCCN guidelines insights: colon cancer, version 2.2018. J Natl Compr Canc Netw 2018;16(4):359-69.

17. Labianca R, Beretta GD, Kildani B, Milesi L, Merlin F, Mosconi S, et al. Colon cancer. Crit Rev Oncol Hematol 2010;74(2):106-33.

18. Ristescu I, Pintilie G, Filip D, Jitca M, Fecheta R, Florescu I, et al. Perioperative anemia and transfusion in colorectal cancer patients. Chirurgia (Bucur) 2019;114(2):234-42.

19. Liu Z, Luo JJ, Pei KY, Khan SA, Wang XX, Zhao ZX, et al. Joint effect of pre-operative anemia and perioperative blood transfusion on outcomes of colon-cancer patients undergoing colectomy. Gastroenterol Rep 2020;8(2):151-7.

20. Patel SV, Brennan KE, Nanji S, Karim S, Merchant S, Booth CM. Peri-operative blood transfusion for resected colon cancer: practice patterns and outcomes in a population-based study. Cancer Epidemiol 2017;51:35-40.

21. Canver MC, Cushing MM, Vagelatos G, Vasovic LV. Visual evidence of a hemolytic transfusion reaction identified by blood bank testing after emergency blood transfusion. Transfusion 2019;59(11):3301-2.
22. Li Y, Zhong X, Cheng G, Zhao C, Zhang L, Hong Y, et al. HsCRP and all-cause, cardiovascular and cancer mortality risk: a meta-analysis. Atherosclerosis 2017;259:75-82.

23. Moutachakkir M, Baraou A, Boukhira A, Chellak S. Immunoanalytical characteristics of C-reactive protein and high sensitivity C-reactive protein. Ann Biol Clin 2017 75(2):225-9.

24. Yoon K, Ryu S, Lee J, Park JD. Higher and increased concentration of hs-CRP within normal range can predict the incidence of metabolic syndrome in healthy men. Diabetes Metab Syndr 2018;12(6):977-83.

25. Lee S, Song IU, Na SH, Jeong DS, Chung SW. Association between long-term functional outcome and change in hsCRP level in patients with acute ischemic stroke. Neurologist 2020;25(5):122-5.

26. Majumdar R, Tavakoli Tameh A, Parent CA. Exosomes mediate LTB4 release during neutrophil chemotaxis. PLoS Biol 2016;14(1):e1002336.

27. Gegin S, Celikel S, Celik D, Pazarli AC. Evaluation of interleukin-6, leukotriene B-4 and nitric oxide levels in exhaled breath condensate of asymptomatic obese individuals: Are obese patients under risk of developing asthma? Eurasian J Med 2020;52(1):25-8.

28. Tang CH, Huang YX, Lin YX, Yuan M. Analysis of Related Factors of Adverse Transfusion Reactions. Zhongguo Shi Yan Xue Ye Xue Za Zhi 2020;28(3):972-6.

29. Encan B, Akin S. Knowledge of blood transfusion among nurses. J Contin Educ Nurs 2019;50(4):176-82.

30. Janssen MP, Van Tilborgh AJ, De Vooght KM, Bokhorst AG, Wiersum-Osselton JC. Direct costs of transfusion reactions-an expert judgement approach. Vox Sang 2018;113(2):143-51.

This is an open access article distributed under the terms of the Creative Commons Attribution-NonCommercial-ShareAlike 3.0 License, which allows others to remix, tweak, and build upon the work non-commercially, as long as the author is credited and the new creations are licensed under the identical terms

This article was originally published in a special issue, "Diagnostic and Therapeutic Advances in Biomedical Research and Pharmaceutical Sciences"

Indian J Pharm Sci 2021:83(5) spl issue "94-100" 